Article

\title{
A Pediatrics Utilization Study in The Netherlands to Identify Active Pharmaceutical Ingredients Suitable for Inkjet Printing on Orodispersible Films
}

\author{
J. Carolina Visser ${ }^{1, *,+} \oplus$, Lisa Wibier ${ }^{1,2, \dagger}$, Olga Kiefer $^{3}$, Mine Orlu ${ }^{4} \oplus$, Jörg Breitkreutz ${ }^{3}$, \\ Herman J. Woerdenbag ${ }^{1}$ and Katja Taxis ${ }^{2}$ \\ 1 Department of Pharmaceutical Technology and Biopharmacy, University of Groningen, \\ Antonius Deusinglaan 1, 9713 AV Groningen, The Netherlands; l.wibier@student.rug.nl (L.W.); \\ h.j.woerdenbag@rug.nl (H.J.W.) \\ 2 Department of PharmacoTherapy, Epidemiology and Economics, University of Groningen, \\ Antonius Deusinglaan 1, 9713 AV Groningen, The Netherlands; k.taxis@rug.nl \\ 3 Institute of Pharmaceutics and Biopharmaceutics, Heinrich-Heine-University Düsseldorf, 40225 Düsseldorf, \\ Germany; olga.kiefer@hhu.de (O.K.); Joerg.Breitkreutz@hhu.de (J.B.) \\ 4 School of Pharmacy, University College London, London WC1N 1AX, UK; m.orlu@ucl.ac.uk \\ * Correspondence: j.c.visser@rug.nl; Tel.: +31-50-3633282; Fax: +31-50-3632500 \\ + These authors contributed equally to this work.
}

Received: 25 January 2020; Accepted: 13 February 2020; Published: 17 February 2020

check for updates

\begin{abstract}
Background: The use of medication in pediatrics, children aged 0-5 years, was explored so as to identify active pharmaceutical ingredients (APIs) suitable for inkjet printing on a plain orodispersible film (ODF) formulation in a pharmacy. Methods: The database IADB.nl, containing pharmacy dispensing data from community pharmacies in the Netherlands, was used to explore medication use in the age group of $0-5$ years old, based on the Anatomical Therapeutic Chemical classification code (ATC code). Subsequently, a stepwise approach with four exclusion steps was used to identify the drug candidates for ODF formulation development. Results: there were 612 Active Pharmaceutical Ingredients (APIs) that were dispensed to the target group, mostly antibiotics. Of the APIs, 221 were not registered for pediatrics, but were used off-label. After the exclusion steps, 34 APIs were examined regarding their suitability for inkjet printing. Almost all of the APIs were sparingly water soluble to practically insoluble. Conclusion: Pharmaceutical inkjet printing is a suitable new technique for ODF manufacturing for pediatric application, however the maximal printed dose as found in the literature remained low. From the selected candidates, only montelukast shows a sufficiently high water-solubility to prepare a water-based solution. To achieve higher drug loads per ODF is ambitious, but is theoretically possible by printing multiple layers, using highly water-soluble APIs or highly loaded suspensions.
\end{abstract}

Keywords: drug utilization research; pediatrics; orodispersible films; pharmaceutical inkjet printing; pharmacy

\section{Introduction}

Drug utilization research is an effective tool to identify the most used medications in patient groups, to assess the quality of prescribing and to facilitate rational drug use [1,2]. It is particularly useful in pediatrics, a heterogeneous group of patients who frequently use off-label medications [2]. In pediatrics, every age group has different needs and copes differently with the available administration forms [3]. For children, there is an apparent lack of age-appropriate dosage forms [2]. This results in manipulations of commercially available dosage forms, which may lead to medication errors [4]. 
Moreover, the adaptation of dosage forms may lead to invalidating the stability profile approved for the original product, altering taste and changing the biopharmaceutical behavior [5]. Furthermore, children aged 0 to 5 years have problems swallowing tablets and capsules.

The pharmaceutical development of medicines for pediatric use is stimulated by the European Medicine Agency [6], including the development of age-appropriate oral dosage forms, such as orodispersible films (ODFs). In short, ODFs are small polymer-based films that are placed in the oral cavity. They subsequently stick to the mucosa and disintegrate quickly. The active pharmaceutical ingredient (API) incorporated into the ODF is swallowed with the saliva and/or absorbed via the oral mucosa. ODFs cannot be spit out because of their sticky nature, and the risk of chocking is practically nil. In addition, ODFs can be prepared on a small scale (e.g., in a hospital or community pharmacy setting) [7], and are therefore considered patient-centric dosage forms [8] and have been accepted in pediatrics [9].

The most used preparation method for ODFs is the solvent casting technique [10]. With this technique, all excipients and APIs are mixed with or dissolved in a (co)solvent. The mixture is cast as a thin film onto a release liner, and is dried and cut into the desired size [7]. Besides this method, printing techniques are suitable for the incorporation of APIs onto ODFs, yielding a personalized oral dosage form [11,12]. Inkjet printing is an emerging technology in the pharmaceutical area, used for the direct labelling of dosage forms, but is also suitable for the API deposition [13]. The significant advantage of this technique is the flexible and precise deposition of the API on a substrate (such as a plain ODF) suitable for small-scale and continuous production [14]. In comparison with the casting of ODFs, less waste is produced. For printing, a pharmaceutical ink is used consisting of the API, a base liquid that easily evaporates and eventual further excipients. The dose is controlled by the drop volume, concentration of API in the ink, printed area, set resolution and number of layers. The prerequisite is that the target API is very well soluble in the base liquid (usually water) and remains stable during the printing process (stable at temperatures above room temperature).

Although medication use in children has been studied frequently, little attention had been paid so far to use these data for the identification of medications for age-appropriate and personalized administration forms such as ODFs. Therefore, in this study, the use of medication in pediatrics, children aged 0 to 5 years, in the Netherlands, is explored so as to identify suitable candidates for the development of ODFs as small-scale extemporaneous preparations. Next, the candidate APIs are examined regarding their suitability for inkjet printing.

\section{Methods}

\subsection{Data Source}

The data in this study are derived from the University of Groningen IADB.nl pharmacy dispensing database. It is a continuously expanding database that contains over 20 years of pharmacy dispensing data. These data are selected from approximately 60 community pharmacies and cover an estimated population of 600,000 patients in the Netherlands. The inclusion of pharmacy dispensing data in the database does not depend on the reimbursement status, or whether a specialist or general practitioner prescribes it. The dispensing data can be considered to be representative for the Netherlands, and has been widely used for drug utilization studies.

Each patient has a unique anonymous identifier; their date of birth and gender are known. In the Netherlands, generally, a patient is registered with one community pharmacy. Therefore, the medication records for each patient are virtually complete, except for over the counter (OTC) drugs and medication dispensed during hospitalization. Each person is individually tracked throughout the database period, and medication records contain information on the date of dispensing, the quantity dispensed, the dose regimen, the prescribing physician and the Anatomical Therapeutic Chemical classification code (ATC code) [15]. 


\subsection{Selection of the Candidates for Development of ODFs}

In this study, all of the dispensed medications for pediatrics (male and female), children from the age of 0 up until and including 5 years of age (on the dispensing date), were explored over a time period of five years (January 2013 until December 2017). All of the ATC codes dispensed were considered, except for B05 (blood substitutes and perfusion solutions), D (dermatological drugs), G01 (gynecological anti-infectives and antiseptics); J06 (immune sera and immunoglobulins), M02 (topical products for joint and muscular pain), P03 (ectoparasiticides, including scabidices, insecticides and repellents), S01 (ophthalmological drugs), V01AA (allergen extracts), V04 (diagnostic agents), V07 (all other non-therapeutic products), V08 (contrast media), V09 (diagnostic radiopharmaceuticals), V10 (therapeutic radiopharmaceuticals) and V20 (surgical dressings). Drugs or products under these ATC codes were considered as not being suitable as candidates for ODF formulation development.

After the selection of the pharmacy dispensing data, a stepwise approach with exclusion steps similar to the ones described in previous research was used to identify candidate APIs for ODF formulation development [1].

In the first step, medications that could not be identified because of an incomplete ATC code (e.g., only having a first level ATC code available in the database), had no legal status as drugs or were mentioned more than once in the pharmacy dispensing database (duplicates) were excluded. Furthermore, as the drug load per ODF is limited [13], all of the medications with a maximum drug load of more than $50 \mathrm{mg}$ per dose were also excluded. The primary source for establishing the dose was the Dutch pediatric formulary [16]. If the dose was not mentioned in this formulary, the Dutch Informatorium Medicamentorum (IM) [17] or the Dutch Farmacotherapeutisch Kompas (FK) [18] were used.

In the second step, medications for non-oral administration routes were excluded. In the third step, off-label use medications were identified. These were, on the one hand, mentioned in the pediatric formulary but not intended for the age group, or, on the other hand, not mentioned in the pediatric formulary but mentioned in the IM or FK only for adult use. These can, however, be of interest for ODF formulation development and were included if dispensed regularly. In the fourth step, the availability of a commercial oral liquid or a standardized preparation in the Netherlands was investigated. These medications are not the first choice for ODF formulation development.

Finally, the manufacturing-related characteristics (water-solubility and taste) were retrieved from the literature $[19,20]$ for all of the APIs that were considered potential candidates for ODF formulation. These characteristics were reviewed to evaluate their suitability for ODF formulation development via inkjet printing.

\subsection{Ethical Statement}

The study database IADB.nl uses de-identified medical records that could not lead to individual patients. According to the Code of Conduct for Health Research by the Foundation Federation of Dutch Medical Scientific Societies, approved by the Dutch Data Protection Authority in 2004 (Foundation Federation of Dutch Medical Scientific Societies 2004), no ethics committee approval is needed for research using anonymous medical records [21].

\section{Results}

The IADB.nl database included 53,542 patients in the age group of 0 to 5 years old. These patients received 227,898 dispensed medications over a period of fove years. This corresponded to 612 different APIs. The ratio of female:male patients was 52.2\%:46.8\%. Table 1 lists the medications per the ATC $1^{\text {st }}$ level. 
Table 1. Distribution of the dispensed medications per the Anatomical Therapeutic Chemical classification code (ATC code) $1^{\text {st }}$ level (ordered according to the frequency of dispensed medications).

\begin{tabular}{cc}
\hline ATC Level & $\begin{array}{c}\text { Number of Dispensed Medications (\% of Total } \\
\text { Dispensed Medications) }\end{array}$ \\
\hline $\mathrm{J}$ (anti-infectives for systemic use) & $67,292(29.5 \%)$ \\
\hline $\mathrm{R}$ (respiratory system) & $59,984(26.3 \%)$ \\
\hline A (alimentary tract and metabolism) & $58,327(25.9 \%)$ \\
\hline $\mathrm{S}$ (sensory organs) & $13,338(5.9 \%)$ \\
\hline $\mathrm{N}$ (nervous system) & $11,619(5.1 \%)$ \\
\hline $\mathrm{H}$ (systemic hormonal preparations, excluding sex \\
hormones and insulins) & $4202(1.8 \%)$ \\
\hline C (cardiovascular system) & $4109(1.8 \%)$ \\
\hline B (blood and blood forming organs) & $3184(1.4 \%)$ \\
\hline M (musculoskeletal system) & $1967(0.9 \%)$ \\
\hline L (antiparasitic products, insecticides and repellents) & $1288(0.6 \%)$ \\
\hline G (genitourinary system and sex hormones) & $1286(0.6 \%)$ \\
\hline V (various) & $1180(0.5 \%)$ \\
\hline
\end{tabular}

In Table 2, the top 15 most dispensed medications are shown.

Table 2. The 15 most dispensed medications, with their ATC codes, number of users and percentage of users (calculated on the total amount of patients, in the age group of 0 until and including 5 years).

\begin{tabular}{ccccc}
\hline & ATC Code & Medications & Number of Users (n) & Percentage of Users (\%) \\
\hline 1 & J01CA04 & Amoxicillin & 25265 & 49.2 \\
\hline 2 & R03AC02 & Salbutamol & 11150 & 20.8 \\
\hline 3 & A07AA02 & Nystatin & 6767 & 12.6 \\
\hline 4 & A06AD15 & Macrogol & 5338 & 10 \\
\hline 5 & J01CR02 & Amoxicilline plus & 4514 & 7.4 \\
\hline 6 & S01AA01 & Chloramphenicol & 3895 & 7.3 \\
\hline 7 & R06AX27 & Desloratidine & 3685 & 6.9 \\
\hline 8 & J01FA10 & Azithromycine & 3376 & 6.3 \\
\hline 9 & A06AD11 & Lactulose & 3272 & 6.1 \\
\hline 10 & S01AA13 & Fusidic acid & 3244 & 6.1 \\
\hline 11 & R01AA07 & Xylometazoline & 2949 & 5.5 \\
\hline 12 & R03BA05 & Fluticasone & 2739 & 5.1 \\
\hline 13 & A06AD65 & Macrogol, combinations & 1687 & 3.2 \\
\hline 14 & J01CF05 & Flucloxacillin & 1679 & 3.1 \\
\hline 15 & J01FA09 & Clarithromycin & 1576 & 2.9 \\
\hline & & & \\
\hline
\end{tabular}


Medications were excluded based on the stepwise approach (see Figure 1). In the first step, 130 medications were excluded-32 medications had an incomplete ATC code, 2 medications had no legal status as drugs in the literature surveyed, 13 duplicates were removed and 83 medications contained a dose unit exceeding $50 \mathrm{mg}$.

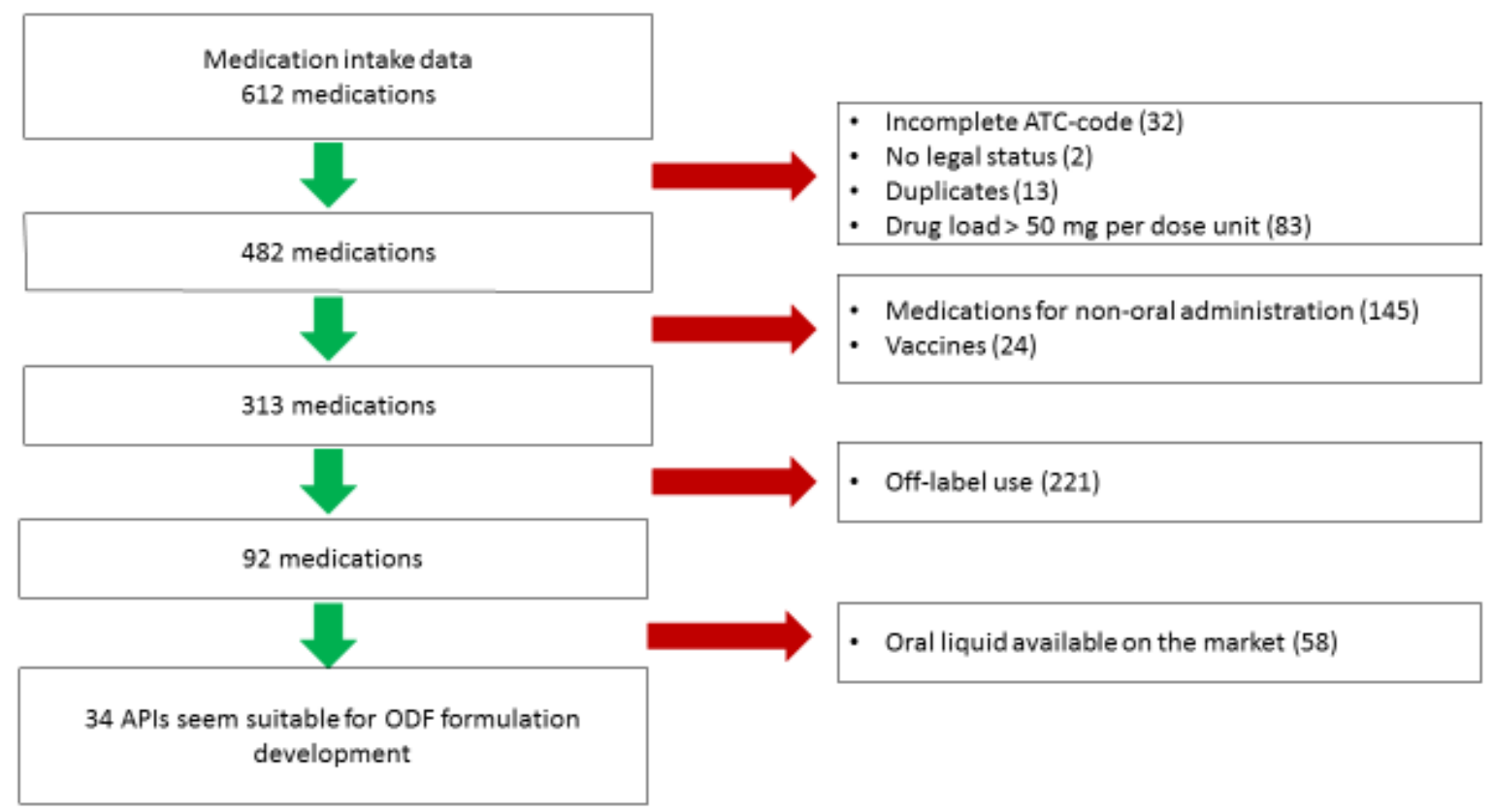

Figure 1. Flowchart for the selection of active pharmaceutical ingredients (APIs) towards orodispersible film (ODF) formulation development.

In the second step, 169 medications were excluded. These were not intended for anoral route (e.g., for inhalation or nasal administration) and 24 medications were vaccines. In the third step, 221 medications were off-label dispensed and initially excluded.

For 92 medications, the availability of a commercial oral liquid or of a standardized preparation in the Netherlands was investigated. These medications were not the first choice for ODF formulation development. After these three selection steps, 34 APIs remained. In Table 3, an overview is given. The APIs were arranged according to water-solubility $(\mathrm{g} / \mathrm{L})$, from practically insoluble or insoluble to freely soluble (according to the definitions set by the European Pharmacopoeia $10^{\text {th }}$ edition) [19]. 
Table 3. Candidates for ODF formulation development via inkjet printing, arranged by water-solubility.

\begin{tabular}{|c|c|c|c|c|c|c|}
\hline & ATC Code & Name & Water Solubility $(\mathrm{g} / \mathrm{L})$ & Taste & Number of Users (n) & Daily Dose ** \\
\hline $1^{*}$ & N06AA04 & Clomipramine & 0.000294 & $\mathrm{n} / \mathrm{a}$ & 1 & $0.25-0.5 \mathrm{mg} / \mathrm{kg} /$ day in two doses \\
\hline 2 & M01AB01 & Indomethacin & 0.000937 & Slightly bitter & 4 & $2 \mathrm{mg} / \mathrm{kg} /$ day in two to four doses \\
\hline 3 & $\mathrm{~A} 06 \mathrm{AB} 02$ & Bisacodyl & 0.00127 & Tasteless & 340 & $5 \mathrm{mg} /$ day \\
\hline 4 & L04AA18 & Everolimus & 0.00163 & $\mathrm{n} / \mathrm{a}$ & 2 & $1.6-9 \mathrm{mg} / \mathrm{m}^{2} /$ day \\
\hline 5 & M01AB05 & Diclofenac & 0.00237 & n/a & 754 & $1-3 \mathrm{mg} / \mathrm{kg} / \mathrm{day}$, in two to four doses \\
\hline 6 & C08DA01 & Verapamil & 0.00447 & $\mathrm{n} / \mathrm{a}$ & 3 & $3-8 \mathrm{mg} / \mathrm{kg} /$ day, in three doses \\
\hline 7 & $\mathrm{~A} 11 \mathrm{CC} 04$ & Calcitriol & 0.00667 & $\mathrm{n} / \mathrm{a}$ & 1 & $0.01-0.1 \mathrm{mics} / \mathrm{kg} / \mathrm{day}$, in two doses \\
\hline 8 & $\mathrm{~N} 02 \mathrm{CX} 01$ & Pizotifen & 0.00706 & n/a & 1 & $0.5-1.5 \mathrm{mg} / \mathrm{day}$, in one to three doses \\
\hline 9 & N05CD08 & Midazolam & 0.00987 & Bitter & 157 & $0.2-0.5 \mathrm{mg} / \mathrm{kg}$ \\
\hline 10 & N05AG02 & Pimozide & 0.01 & $\mathrm{n} / \mathrm{a}$ & 1 & $0.5-1 \mathrm{mg} /$ day \\
\hline 12 & N06AA02 & Imipramine & 0.0182 & $\mathrm{n} / \mathrm{a}$ & 3 & $20-30 \mathrm{mg} /$ day \\
\hline 13 & N04AA02 & Biperiden & 0.0251 & n/a & 9 & $1-2 \mathrm{mg}$, one to three times daily \\
\hline 14 & N05CD02 & Nitrazepam & 0.0299 & $\mathrm{n} / \mathrm{a}$ & 9 & $2.5-5 \mathrm{mg} /$ day \\
\hline 15 & N05BA01 & Diazepam & 0.050 & Bitter aftertaste & 501 & $0.1-0.8 \mathrm{mg} / \mathrm{kg} /$ day, in four doses \\
\hline y16 & H02AB07 & Prednisone & 0.07754 & Bitter aftertaste & 8 & $1-2 \mathrm{mg} / \mathrm{kg}$, in two doses \\
\hline 17 & C05AA12 & Triamcinolone & 0.080 & Bitter & 2 & $<35 \mathrm{~kg}: 4-12 \mathrm{mg} /$ day \\
\hline 18 & H01BA02 & Desmopressin & 0.11 & $\mathrm{n} / \mathrm{a}$ & 43 & $0.2 \mathrm{mg} /$ day \\
\hline 19 & C03BA04 & Chlorthalidone & 0.12 & $\mathrm{n} / \mathrm{a}$ & 3 & $0.5-1 \mathrm{mg} / \mathrm{kg}$, max $1.7 \mathrm{mg} / \mathrm{kg}$ per $48 \mathrm{~h}$ \\
\hline 20 & H02AA02 & Fludrocortisone & 0.14 & $\mathrm{n} / \mathrm{a}$ & 11 & $50-150$ mics/day, in two doses \\
\hline 21 & N03AX09 & Lamotrigine & 0.17 & n/a & 35 & $0.3-1.2 \mathrm{mg} / \mathrm{kg}$ \\
\hline 22 & N05BA04 & Oxazepam & 0.179 & Bitter & 27 & 10-30 mg per day, in three to four doses \\
\hline 23 & $\mathrm{~A} 02 \mathrm{BC} 01$ & Omeprazole & 0.359 & $\mathrm{n} / \mathrm{a}$ & 453 & $1 \mathrm{mg} / \mathrm{kg} /$ day in one to two doses, $\max 40 \mathrm{mg} /$ day \\
\hline 24 & J04BA02 & Dapsone & 0.38 & Slightly bitter & 2 & $1-1.5 \mathrm{mg} / \mathrm{kg} / \mathrm{day}$ \\
\hline 25 & N05BB01 & Hydroxyzine & 0.428 & Bitter & 7 & $1-2 \mathrm{mg} / \mathrm{kg} / \mathrm{day}, \max 100 \mathrm{mg} / \mathrm{day}$ \\
\hline 26 & N07CA02 & Cinnarizine & 0.75 & Bitter & 3 & $12.5 \mathrm{mg}$, if necessary, three to four times per day \\
\hline 27 & R06AE05 & Meclozine & 1 & tasteless & 1 & $6.25 \mathrm{mg}$, if necessary, three to four times per day \\
\hline 28 & N07AA02 & Pyridostigmine & 1.04 & tasteless & 18 & $10 \mathrm{mg} / \mathrm{day}, \mathrm{max} 100-500 \mathrm{mg}$ in three doses \\
\hline 29 & N02AE01 & Buprenorphine & 1.680 & Bitter & 3 & 15 mics $/ \mathrm{kg} /$ day in three doses \\
\hline 30 & L04AX03 & Methotrexate & 2.6 & $\mathrm{n} / \mathrm{a}$ & 28 & $10-15 \mathrm{mg} / \mathrm{m}^{2} /$ dose, once per week \\
\hline 31 & V03AH01 & Diazoxide & 2.85 & $\mathrm{n} / \mathrm{a}$ & 1 & $5 \mathrm{mg} / \mathrm{kg} /$ day, in two doses \\
\hline 32 & N03AX11 & Topiramate & 9.8 & Bitter & 11 & $1-3 \mathrm{mg} / \mathrm{kg} /$ day \\
\hline 33 & M04AC01 & Colchicine & 10 & $\mathrm{n} / \mathrm{a}$ & 7 & $0.5-1 \mathrm{mg} / \mathrm{day}$, in one to two doses \\
\hline 34 & R03DC03 & Montelukast & $>100$ & $\mathrm{n} / \mathrm{a}$ & 178 & $4 \mathrm{mg}$ per day \\
\hline
\end{tabular}

* $<0.1 \mathrm{~g} / \mathrm{L}=$ practically insoluble or insoluble (red); $0.1-1 \mathrm{~g} / \mathrm{L}=$ very slightly soluble (orange); $1-10 \mathrm{~g} / \mathrm{L}=$ slightly soluble (dark yellow); 30-100 g/L = sparingly soluble (light yellow, not applicable in this table); $100-1000 \mathrm{~g} / \mathrm{L}=$ freely soluble (green). ${ }^{*}[16-18]$ 


\section{Discussion}

The most frequently dispensed medications for pediatrics in the age group of $0-5$ years were anti-infectives for systemic use. For almost $50 \%$ of the patients, the broad-spectrum antibiotic Amoxicillin was dispensed. This antibiotic is commonly used in the treatment of mild or moderate pneumonia or ear infections [16]. Furthermore, medications to treat disorders of the respiratory system (e.g., salbutamol) and medication to treat disorders of the alimentary tract were frequently dispensed (e.g., macrogol). The dose of antibiotics is usually too high to fit in an ODF.

Of the 612 medications, two had no legal status as medicine- biotin and ferrous chloride. Biotin is used as a food supplement for the treatment of biotinidase deficiency. Ferrous chloride is used as a trace element.

Vaccines were excluded in the second step. Vaccines are prone to degradation if taken orally and if exposed to high temperatures. They can, however, be stabilized with sugars, subsequently incorporated into ODFs and are absorbed via the buccal or sublingual route upon administration [13]. The printing of vaccines via inkjet printing is, because of the usually high temperatures involved, not possible. It could be feasible at low temperatures, if a bioprinter is used.

Of the 612 medications, 221 were not registered for pediatrics and thus used off-label. This is very common for the age group [2]. Off-label use is referred to by the European Commission as "any intentional use of an authorized product not covered by the terms of its marketing authorization and therefore not in accordance with the Summary of Product Characteristics". This may, for example, be the use of a product for a different indication; the use of a different dosage, dosing frequency or duration of use; use of a different method of administration or use by a different patient group (e.g., children instead of adults) [22]. Off-label medications are prescribed if age-appropriate medications are not available. For health-care professionals, it is then the only option for treatment. Recently, the European Academy of Pediatrics and the European Society for Developmental Perinatal and Pediatric Pharmacology published recommendations on how and when to prescribe off-label medications [23].

Of the off-label dispensed medications, 220 were used by less than 10 patients, and for this reason, they were not the first choice for ODF formulation development. An example is gemfibrozil, which was used by one patient. It is indicated for the treatment of hypercholesterolemia in adults. The Summary of Products Characteristics of gemfibrozil states that use in children is not recommended because of a lack of data [24]. In the literature, however, use in pediatrics is described to treat neuronal ceroid lipofuscinosis $[25,26]$. One medication, ivermectin, was used by 38 patients. It was excluded for further research based on the safety aspect. In the literature, the safety of ivermectin in children weighing $<15 \mathrm{~kg}$ has not been established [18]. Considering that the majority of children of 4-5 years of age have a bodyweight higher than $15 \mathrm{~kg}$, ivermectin may be a candidate for further research if dispensed frequently.

After three exclusion steps, 92 medications were selected for further research. For 58 medications, a commercial oral liquid or an injection fluid (to be used as oral liquid) were available. Oral liquids have, for many years, been the dosage form of choice for pediatrics [27], and for that reason, these 58 medications were not regarded as the first choice for ODF formulation development. However, it is important to keep in mind that oral liquids have limitations, namely: formulations are not suitable for children with fluid restriction; the formulations possess a relatively short shelf life (due to chemical and/or microbiological stability limitations); accurate dosing is not always possible with the use of, e.g., a measuring cup and children may spit out the dose if the smell and taste is not acceptable for them $[5,27,28]$. Moreover, in case of a shortage of commercially available medications, age-appropriate dosage forms, such as ODFs, can be compounded and tailor-made in a pharmacy.

The acceptability of formulations for pediatrics have been under investigation since the development and establishment of the European Pediatric Regulation [6]. The taste is one of the key factors for the acceptance of a dosage form $[29,30]$. ODFs have been studied in children, and they positively respond to this dosage form [9]. The specific dimensions of the ODFs, the fast disintegration profile and the organoleptic properties contribute to their acceptability, and hence will positively influence medicine adherence [9]. 
The remaining 34 APIs were examined regarding their suitability for inkjet printing. A prerequisite is that the target API is very water soluble if water is used as base liquid, or otherwise, it is very soluble in the target base liquid. The more soluble the API, the higher the possible API content of the ink. Considering the list of final candidates for ODF formulation in pediatrics (Table 3), it is obvious that most of them are very slightly to practically insoluble in water. Only montelukast shows a sufficient water-solubility to prepare a water-based solution with a therapeutic effective strength. For the other candidates, a change in $\mathrm{pH}$ value, the addition of co-solvents and surfactants or the sole use of organic solvents may facilitate possibilities for formulation into a printed ODF.

The safety of the excipients in relation to the age group is an important issue in the development of a medicinal product [6]. Therefore, it must be ensured that the excipients are safe and suitable for use in pediatrics, and that the residual solvent content is below the accepted limit [14]. To circumvent limitations due to solubility, nanosuspension inks can be prepared [31,32]. The most critical issue with inkjet printing is the clogging of nozzles by particles of an inappropriate size, and the recrystallized API or excipients due to the solvent evaporating too quickly. Failed nozzles lead to an underdosing of the API. Moreover, it must also be ensured that the ODFs are not damaged or dissolved by the ink applied. There is a possibility to create porous ODFs for higher liquid absorption, containing mesoporous silica particles or foamed hydroxypropyl methylcellulose [33-35]. However, the in vivo profile has to be investigated if the mouthfeel stays acceptable and if the dissolution profiles change.

Compared with adults, the oral cavity in pediatrics is small. Therefore, small ODF sizes (e.g., $1.8 \times 1.8 \mathrm{~cm}$ ) are preferred. Consequently, the printed ODF area and thus drug load is limited. It should however be feasible to incorporate $25 \mathrm{mg}$ into a small size ODF, by printing multiple layers and using highly water soluble APIs or highly loaded suspensions. Higher dosages can only be achieved by the intake of several ODFs at the same time. A dosage of, e.g., $50 \mathrm{mg}$ implies the intake of two ODFs, which should be acceptable.

From the final selection of APIs, diclofenac [36], indomethacin [32,37], montelukast [38] and prednisolone (frequently dispensed instead of prednisone, as listed in Table 3) [39] have been already successfully printed using the inkjet technique on ODFs or transparency sheets. In the case of montelukast and prednisolone, the therapeutic dose was achieved, however, in the case of diclofenac and indomethacin, the printed dose remained too low. An option is, as mentioned before, to print multiple layers; however, this may lead to morphological changes of the film substrates [37]. Pharmaceutical inkjet printing is a suitable technique for ODF manufacturing for pediatric application. The literature reveals that it is possible to print therapeutically applied doses of a number of the selected APIs [38,39].

\section{Conclusions}

In conclusion, the most dispensed medications in the target group were antibiotics and off-label use medications, which is very common in pediatrics.

From the database, 34 APIs were identified as candidates for ODF formulation development via inkjet printing. Only montelukast showed sufficient water-solubility to prepare a water-based solution of a therapeutically effective strength. For most of the APIs, organic solvents are needed or nanosuspensions can be used. To achieve higher drug loads per ODF is ambitious, but is theoretically possible by printing multiple layers and using highly water soluble APIs or highly loaded suspensions.

Establishing inkjet printing technology in pharmacies requires a good process understanding as well as guaranteed safety with regard to the residual solvents in the final product. The printing of ODFs is, however, a step forward in the development of age-appropriate and thus individualized dosage forms.

Author Contributions: Conceptualization, J.C.V. and L.W.; Data curation, J.C.V. and L.W.; Writing-original draft, J.C.V., L.W., O.K. and M.O.; Writing-review and editing, J.C.V., L.W., J.B., H.J.W. and K.T. All authors have read and agreed to the published version of the manuscript.

Funding: This research received no external funding.

Conflicts of Interest: The authors declare no conflict of interest. 


\section{References}

1. Visser, J.C.; Wibier, L.; Mekhaeil, M.; Woerdenbag, H.J.; Taxis, K. Orodispersible films as a personalized dosage form for nursing home residents, an exploratory study. Int. J. Clin. Pharm. 2020, 1-9, (submitted, minor revisions). [CrossRef]

2. Neubert, A.; Taxis, K.; Wong, A.C.K. Drug utilization in the paediatric population. In Drug Utilization Research Methods and Applications; Elseviers, M., Ed.; Wiley Blackwell: Chichester, UK, 2016; pp. 248-258.

3. European Medicines Agency (EMA). Reflection Paper: Formulations of Choice for the Paediatric Population. 2006. Available online: https://www.ema.europa.eu/en/documents/scientific-guideline/reflection-paperformulations-choice-paediatric-population_en.pdf (accessed on 27 November 2019).

4. Chedoe, I.; Molendijk, H.; Hospes, W.; Van den Heuvel, E.R.; Taxis, K. The effect of a multifaceted educational intervention on medication preparation and administration errors in neonatal intensive care. Arch. Dis. Child Fetal Neonatal Ed. 2012, 97, F449-F455. [CrossRef] [PubMed]

5. Visser, J.C.; Woerdenbag, H.J.; Hanff, L.M.; Frijlink, H.W. Personalized medicine in pediatrics: The clinical potential of orodispersible films. AAPS PharmSciTech 2017, 18, 267-272. [CrossRef] [PubMed]

6. European Medicines Agency (EMA): Guideline on Pharmaceutical Development of Medicines for Paediatric Use 2013. Available online: https://www.ema.europa.eu/en/documents/scientific-guideline/guidelinepharmaceutical-development-medicines-paediatric-use_en.pdf (accessed on 27 November 2019).

7. Visser, J.C.; Woerdenbag, H.J.; Crediet, S.; Gerrits, E.; Lesschen, M.A.; Hinrichs, W.L.J.; Breitkreitz, J.; Frijlink, H.W. Orodispersible films in individualized pharmacotherapy: The development of a formulation for pharmacy preparations. Int. J. Pharm. 2015, 478, 155-163. [CrossRef] [PubMed]

8. Liu, F.; Ranmal, S.R.; Batchelor, H.K.; Orlu-Gul, M.; Ernest, T.B.; Thomas, I.W.; Flanagan, T.; Tuleu, C. Patient-centred pharmaceutical design to improve acceptability of medicines: Similarities and differences in paediatric and geriatric populations. Drugs 2014, 74, 1871-1889. [CrossRef] [PubMed]

9. Orlu, M.; Ranmal, S.R.; Sheng, Y.; Tuleu, C.; Seddon, P. Acceptability of orodispersible films for delivery of medicines to infants and preschool children. Drug Deliv. 2017, 24, 1243-1248. [CrossRef] [PubMed]

10. Krampe, R.; Visser, J.C.; Frijlink, H.W.; Breitkreutz, J.; Woerdenbag, H.J.; Preis, M. Oromucosal film preparations: Points to consider for patient centricity and manufacturing processes. Expert Opin. Drug Deliv. 2016, 13, 493-506. [CrossRef]

11. Sandler, N.; Määttänen, A.; Ihalainen, P.; Kronberg, L.; Meierjohann, A.; Viitala, T.; Peltonen, J. Inkjet printing of drug substrates and use of porous substrates-towards individualized dosing. J. Pharm. Sci. 2011, 8, 3386-3395. [CrossRef]

12. Öblom, H.; Sjöholm, E.; Rautamo, M.; Sandler, N. Towards Printed Pediatric Medicines in Hospital Pharmacies: Comparison of 2D and 3D-Printed Orodispersible Warfarin Films with Conventional Oral Powders in Unit Dose Sachets. Pharmaceutics 2019, 11, 334. [CrossRef]

13. Tian, Y.; Orlu, M.; Woerdenbag, H.J.; Scarpa, M.; Kiefer, O.; Kottke, D.; Sjöblom, E.; Öblom, H.; Sandler, N.; Hinrichs, W.L.J.; et al. Oromucosal films: From patient centricity to production by printing techniques. Expert Opin. Drug Deliv. 2019, 16, 981-993. [CrossRef]

14. Thabet, Y.; Lunter, D.; Breitkreutz, J. Continuous Inkjet Printing of Enalapril Maleate onto Orodispersible Film Formulations. Int. J. Pharm. 2018, 546, 180-187. [CrossRef] [PubMed]

15. IADB Pharmacy Dispensing Database. Available online: http://iadb.nl/ (accessed on 27 November 2019).

16. Dutch Paediatric Formulary (Kinderformularium). Available online: https://www.kinderformularium.nl/ (accessed on 27 November 2019).

17. Informatorium Medicamentorium. Available online: www.kennisbank.knmp.nl (accessed on 27 November 2019).

18. Farmacotherapeutisch Kompas. Available online: https://www.farmacotherapeutischkompas.nl/ (accessed on 27 November 2019).

19. European Pharmacopoeia. Available online: https://pheur.edqm.eu/home (accessed on 27 November 2019).

20. Pubchem. Available online: https://pubchem.ncbi.nlm.nih.gov/ (accessed on 27 November 2019).

21. Federa. Available online: www.federa.org/federa-english (accessed on 9 February 2020).

22. European Commission. Study on Off-Label Use of Medicinal Products in the European Union. Available online: https://ec.europa.eu/health/sites/health/files/files/documents/2017_02_28_final_study_report_on_ off-label_use_pdf (accessed on 27 November 2019). 
23. Schrier, L.; Hadjipanayis, A.; Stiris, T.; Ross-Russell, R.I.; Valiulis, A.; Turner, M.A.; Zhao, W.; De Cock, P.; de Wildt, S.N.; Allegaert, K.; et al. Off-label use of medicines in neonates, infants, children, and adolescents: A joint policy statement by the European Academy of Paediatrics and the European society for Developmental Perinatal and Pediatric Pharmacology. Eur. J. Pediatr. 2020. [CrossRef] [PubMed]

24. Summary of Products Characteristics Gemfibrozil. Available online: https://www.medicines.org.uk/emc/ product/132/smpc (accessed on 27 November 2019).

25. Kim, K.; Kleinman, H.K.; Lee, H.J.; Pahan, K. Safety and potential efficacy of gemfibrozil as a supportive treatment for children with late infantile neuronal ceroid lipofuscinosis and other lipid storage disorders. Orphanet J. Rare Dis. 2017, 12, 113. [CrossRef] [PubMed]

26. Kohlschütter, A.; Schulz, A.; Bartsch, U.; Storch, S. Current and Emerging Treatment Strategies for Neuronal Ceroid Lipofuscinoses. CNS Drugs 2019, 33, 315-325. [CrossRef] [PubMed]

27. Meyers, R. A wish list for drug development in pediatrics. J. Pharm. Sci. 2019, 109, 939-943. [CrossRef] [PubMed]

28. Van Riet-Nales, D.A.; de Neef, B.J.; Schobben, A.F.; Ferreira, J.A.; Egberts, T.C.; Rademaker, C.M. Acceptability of different oral formulations in infants and preschool children. Arch. Dis. Child. 2013, 98, 725-731. [CrossRef]

29. Thabet, Y.; Klingmann, V.; Breitkreutz, J. Drug formulations: Standards and novel strategies for drug administration in pediatrics. J. Clin. Pharmacol. 2018, 58, S26-S35. [CrossRef]

30. Mistry, P.; Batchelor, H. SPaeDD-UK project (Smart Paediatric Drug Development-UK), Evidence of acceptability of oral paediatric medicines: A review. J. Pharm. Pharmacol. 2017, 69, 361-376. [CrossRef]

31. Pardeike, J.; Strohmeier, D.M.; Schrödl, N.; Voura, C.; Gruber, M.; Khinast, J.G.; Zimmer, A. Nanosuspensions as advanced printing ink for accurate dosing of poorly soluble drugs in personalized medicines. Int. J. Pharm. 2011, 420, 93-100. [CrossRef]

32. Kollamaram, G.; Hopkins, S.C.; Glowacki, B.A.; Croker, D.M.; Walker, G.M. Inkjet printing of paracetamol and indomethacin using electromagnetic technology: Rheological compatibility and polymorphic selectivity. Eur. J. Pharm. Sci. 2018, 115, 248-257. [CrossRef]

33. Genina, N.; Fors, D.; Palo, M.; Peltonen, J.; Sandler, N. Behavior of printable formulations of loperamide and caffeine on different substrates-effect of print density in inkjet printing. Int. J. Pharm. 2013, 453, 488-497. [CrossRef]

34. Iftimi, L.D.; Edinger, M.; Bar-Shalom, D.; Rantanen, J.; Genina, N. Edible solid foams as porous substrates for inkjet-printable pharmaceuticals. Eur. J. Pharm. Biopharm. 2019, 136, 38-47. [CrossRef] [PubMed]

35. Edinger, M.; Bar-Shalom, D.; Sandler, N.; Rantanen, J.; Genina, N. QR encoded smart oral dosage forms by inkjet printing. Int. J. Pharm. 2018, 536, 138-145. [CrossRef] [PubMed]

36. Eleftheriadis, G.K.; Monou, P.K.; Bourppoulos, N.; Fatouris, D.G. In Vitro Evaluation of 2D-Printed Edible Films for the Buccal Delivery of Diclofenac Sodium. Materials 2018, 11, 864. [CrossRef]

37. Wickstrom, H.; Palo, M.; Rijckaert, K.; Kolakovoc, R.; Nyman, J.O.; Määttänen, A.; Ihalainen, O.; Peltonen, J.; Genina, N.; de Beer, T.; et al. Improvement of dissolution rate of indomethacin by inkjet printing. Eur. J. Pharm. Sci. 2015, 75, 91-100. [CrossRef]

38. Edinger, M.; Iftimi, L.D.; Markl, D.; Al-Sharabi, M.; Bar-Shalom, D.; Rantanen, J.; Genina, N. Quantification of Inkjet-Printed Pharmaceuticals on Porous Substrates Using Raman Spectroscopy and Near-Infrared Spectroscopy. AAPS PharmSciTech 2019, 20, 207. [CrossRef]

39. Vakili, H.; Wickström, H.; Desei, D.; Preis, M.; Sandler, N. Application of a handheld NIR spectrometer in prediction of drug content in inkjet printed orodispersible formulations containing prednisolone and levothyroxine. Int. J. Pharm. 2017, 524, 414-423. [CrossRef]

(C) 2020 by the authors. Licensee MDPI, Basel, Switzerland. This article is an open access article distributed under the terms and conditions of the Creative Commons Attribution (CC BY) license (http://creativecommons.org/licenses/by/4.0/). 